\title{
Correction to: Interplay of stromal tumor-infiltrating lymphocytes, normal colonic mucosa, cancer-associated fibroblasts, clinicopathological data and the immunoregulatory molecules of patients diagnosed with colorectal cancer
}

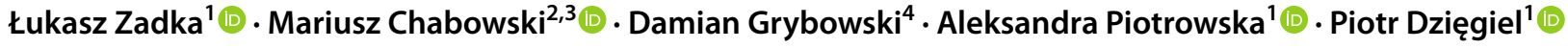

Published online: 13 September 2021

(c) The Author(s) 2021

\section{Correction to: \\ Cancer Immunology, Immunotherapy \\ (2021) 70:2681-2700 \\ https://doi.org/10.1007/s00262-021-02863-1}

The original version of this article unfortunately contained a mistake. The correct information is given below.

Affiliation listed at the 1st position should be as follows: Department of Human Morphology and Embryology, Division of Histology and Embryology, Wroclaw Medical University, Chałubińskiego 6a, 50-368 Wrocław, Poland. is:

At the reference position number 54 the current citation

Zadka Ł, Piotrowska A, Opalińska A, HaczkiewiczLeśniak K, Grybowski D, Ceremuga I, Chabowski M, Dzięgiel P (2020) Comparative analysis of exosome markers and extracellular vesicles between colorectal cancer and cancer-associated normal colonic mucosa. Pol Arch Intern Med. https://doi.org/10.20452/pamw.15462.

The original article can be found online at https://doi.org/10.1007/ s00262-021-02863-1.

Łukasz Zadka

ceadr7@gmail.com

1 Department of Human Morphology and Embryology, Division of Histology and Embryology, Wroclaw Medical University, Chałubińskiego 6a, 50-368 Wrocław, Poland

2 Department of Clinical Proceedings, Faculty of Health Science, Wroclaw Medical University, Wroclaw, Poland

3 Department of Surgery, 4Th Military Teaching Hospital, Wrocław, Poland

4 Department of Surgery, University of Chicago, Chicago, USA
An appropriate citation should be as follows:

Zadka Ł, Piotrowska A, Opalińska A, HaczkiewiczLeśniak K, Grybowski D, Ceremuga I, Chabowski M, Dzięgiel P (2020) Comparative analysis of exosome markers and extracellular vesicles between colorectal cancer and cancer-associated normal colonic mucosa. Pol Arch Intern Med 130(7-8):640-648. https://doi.org/10.20452/pamw.15462.

Open Access The article is distributed under the terms of the Creative Commons Attribution-NonCommercial 4.0 International License (http://creativecommons.org/licenses/by-nc/4.0/), which permits any noncommercial use, duplication, adaptation, distribution and reproduction in any medium or format, as long as you give appropriate credit to the original author(s) and the source, a link is provided to the Creative Commons license and any changes made are indicated.

Publisher's Note Springer Nature remains neutral with regard to jurisdictional claims in published maps and institutional affiliations. 